\title{
I never knew anyone who peed on themselves on purpose: Exploring adolescent and adult women's lay language and discourse about bladder health and function
}

\author{
Beverly Rosa Williams $\mathbf{P h D}^{\mathbf{1}}$ (1) | Jesse Nodora DrPH $^{2}$ | \\ Diane K. Newman DNP, ANP-BC, FAAN ${ }^{3}$ (1) | Lisa Kane Low PhD CNM FAAN ${ }^{4}$ | \\ Aimee S. James PhD, MPH ${ }^{5}$ Deepa R. Camenga MD MHS ${ }^{6}$ | \\ Jeni Hebert-Beirne PhD, MPH $^{7}$ | Sonya S. Brady PhD $^{8}$ ( ) \\ Cecilia T. Hardacker MSN, RN, CNL ${ }^{9,10}$ | Ariana L. Smith MD $^{11}$ (1) | \\ Shayna D. Cunningham PhD ${ }^{12}$ | Kathryn L. Burgio PhD ${ }^{13,14}$ | \\ Prevention of Lower Urinary Tract Symptoms (PLUS) Research Consortium
}

${ }^{1}$ Department of Medicine, Division of Gerontology, Geriatrics and Palliative Care, University of Alabama at Birmingham (UAB), Alabama
2 Department of Family Medicine and Public Health, University of California-San Diego Moores Cancer Center, San Diego, California
${ }^{3}$ Adjunct Professor of Urology in Surgery, Department of Surgery, Perelman School of Medicine, University of Pennsylvania, Pennsylvania
${ }^{4}$ Women's Studies and Department of Obstetrics and Gynecology, University of Michigan, Michigan
${ }^{5}$ Division of Public Health Sciences, Department of Surgery, Washington University School of Medicine, Washington
${ }^{6}$ Department of Emergency Medicine (Pediatrics), Section of Research, Yale School of Medicine, Connecticut
${ }^{7}$ Community Health Sciences, School of Public Health, University of Illinois at Chicago, Illinois
${ }^{8}$ Division of Epidemiology \& Community Health, University of Minnesota School of Public Health, Minnesota
${ }^{9}$ Department of Education, Center for Education, Research and Advocacy, Howard Brown Health, Chicago, Illinois
${ }^{10}$ Adjunct Instructor, Rush University College of Nursing, Illinois
${ }^{11}$ Division of Urology, Department of Surgery, University of Pennsylvania Health System, Pennsylvania
${ }^{12}$ Social and Behavioral Sciences Department, Yale School of Public Health, Connecticut
${ }^{13}$ Department of Medicine, Division of Gerontology, Geriatrics and Palliative Care, Geriatric Research, Education and Clinical Center,
Department of Veterans Affairs, University of Alabama at Birmingham (UAB) and Birmingham/Atlanta, Alabama
${ }^{14}$ National Institute of Diabetes and Digestive and Kidney Diseases, National Institutes of Health, Bethesda, Maryland

Correspondence

Beverly R. Williams, PhD, 933 19th Street South, CH19, 218K, Birmingham,

AL 35233.

Email: Beverly.williams@uabmc.edu

\section{Funding information}

National Institute of Diabetes and Digestive and Kidney Diseases (NIDDK) and National Institute on Aging (NIA), Grant/Award Number: U01DK106786,

U01DK106827, U01DK106853,

U01DK106858, U01DK106892,

U01DK106893, U01DK106898,

U01DK106908; National Institutes of

Health (NIH); NIH Office on Research in

\begin{abstract}
Aims: This analysis explored and characterized adolescent and adult women's lay language and discourse related to bladder health/function.

Methods: Forty-four focus groups were conducted across seven United States research centers with 360 adolescents and adult women, organized by six age categories. Multilevel content analyses classified emergent themes. A transdisciplinary lens and inductive approach guided data interpretation. Interpretive insights were validated by a community engagement panel.

Results: A repertoire of bladder function terms emerged, including explicit functional terms, formal and polite euphemistic terms, and informal familiar terms, as well as cultural and regional metaphors and idioms. Terminology usage was historically grounded, developmental, and cumulative across the life
\end{abstract}


Women's Health and the NIH Office of Behavioral and Social Science course. Lay discourse was contextual and affectively valent, suggesting unspoken, commonly understood, situation-based "rules" for talking about bladder function. Discourse appeared to be siloed within family and friendship circles. Adolescents and adult women often described, rather than named, bladder sensations or problems. Terminology for bladder issues tended to minimize severity and frequency, with medical language only relevant to extreme examples and not applicable to mild episodes.

Conclusions: A definitional discordance between medical and lay views of bladder problems was identified, signifying a need to clarify the meaning of medical terms for lay persons. Adolescents and adult women do not have or use standardized precise terminology for bladder health and function, relying instead on social convention and interpersonal context. Findings can be used to foster shared understandings between lay persons and health professionals, informing development of clinical, research, and public health initiatives to promote bladder health.

\section{K E Y W O R D S}

adolescents, adult women, focus groups, lower urinary tract symptoms, qualitative research, urinary bladder

\section{\begin{tabular}{l|l}
1 & INTRODUCTION
\end{tabular}}

A substantial body of research is examining the need to render medical terminology more accessible, understandable, and acceptable by lay persons across a wide range of conditions and settings. ${ }^{1,2}$ There is a corresponding effort to characterize lay terminology about health and function and explore its utility in healthcare communication. ${ }^{3,4}$ At the intersection of these lines of inquiry there is a dilemma concerning how to bridge the gap between the specialized character of scientific medical language and the nuanced nature of lay terminology.

Terminology for bladder health and lower urinary tract symptoms (LUTS) is a case in point. The medical profession has worked to standardize and refine terminology on bladder function and LUTS through consensus documents within professional societies and via discourse in peer-reviewed journals. ${ }^{5}$ It has been observed that lay usage does not coincide with scientific medical terminology, ${ }^{6}$ and the lay public does not have a shared repository of terminology or common arena for discourse about bladder health.

Studies exploring lay terminology and discourse about bladder health and function demonstrate the need to identify a body of scientifically-sound, lay-friendly terminology to inform the development of research instruments for symptom assessment and public health initiatives for promoting bladder health, preventing LUTS, and assisting individuals in communicating with their healthcare providers about bladder health issues. Notably, focus groups conducted among participants with and without overactive bladder symptoms revealed no difference in descriptions of regular and urgent sensations to urinate, ${ }^{7,8}$ with "pressure" and "tingling" emerging as two distinct types of bladder sensations in both populations. ${ }^{9}$ Qualitative explorations of individuals' experiences of LUTS provide lay descriptions of the subjective and complex nature of these conditions ${ }^{10,11}$ and their consequences, including personal disruption and bodily disaffection, ${ }^{12}$ emotional distress and interpersonal strain, ${ }^{13}$ and discomfort and desire for relief. ${ }^{14}$ Further, another study analyzed postings from an on-line self-help forum and used the naturalistic language of participants to explore the lived experience of women with recurrent urinary tract infections, giving voice to a more comprehensive array of disabling symptoms than are found in the medical literature. ${ }^{15}$

The purpose of this paper is to characterize the attributes of lay language and terminology related to bladder health and function and describe the landscape of lay discourse among a diverse, community-based sample of adolescents, and adult women across a broad age range.

\section{MATERIALS AND METHODS}

\subsection{Overview}

The Study of Habits, Attitudes, Realities, and Experiences (SHARE), is a qualitative study of the Prevention of Lower Urinary Tract Symptoms (PLUS) Research Consortium, a transdisciplinary network of seven geographically diverse 
research centers and a Scientific and Data Coordinating Center. PLUS was established to expand research related to the prevention of LUTS and the promotion of bladder health in adolescent and adult women. ${ }^{16}$ The SHARE study used focus group methodology to explore women's and adolescents' experiences, perceptions, beliefs, knowledge, and behaviors related to bladder health and function across the life course. This paper reports an analysis of lay language and terminology used to describe bladder health and function, articulating social processes that shape lay discourse.

\section{2 | Participants}

Participants were adolescents and adult women recruited at each of the seven research centers, using a variety of recruitment methods including flyers, on-line postings, word of mouth, email announcements, and referral by community partners. Applying a life course perspective, participants were recruited and organized into six age categories: early adolescents: 11 to 14 years; adolescents: 15 to 17 years; young adult women: 18 to 25 years; adult women: 26 to 44 years; middle-aged women: 45 to 64 years; and older women: $65+$ years.

Participants were eligible if they were 11 years of age or older, assigned female at birth, spoke English/Spanish, were able to read and provide written informed consent (or assent and parental permission for those 11-14 years of age), and self-reported the absence of any physical or mental condition that would impede participation. To provide additional context, participants were asked about the language spoken at home, but this was not an inclusion/exclusion criterion. Current pregnancy was an exclusion criterion due to the known effects of pregnancy on LUTS. To ensure a wide range of bladder experiences, participants were included without regard to LUTS status, which was only assessed following focus group participation.

We aimed to recruit a sample that was diverse with respect to race, ethnicity, education, socioeconomic states, physical/health conditions, LUTS status, geography (urban/rural), and language, including focus groups conducted in Spanish. Recruitment was coordinated across centers to strategically determine the composition of each focus group and ensure overall study diversity.

\section{3 | Procedures}

Between July 2017 and April 2018, focus groups were conducted within age categories to encourage comfort and open communication among participants based on shared social context and similar life experiences.

The sessions lasted about 90 minutes and were conducted in rural and urban community settings, such as libraries, universities, community organization meeting spaces, and churches. Focus groups were conducted by female moderators who received standardized training in qualitative research principles adopted by the PLUS Consortium, best practices for focus group research, and the SHARE study protocol.

Each session followed a semi-structured focus group guide developed by the investigators, informed by the PLUS conceptual framework and based on the social ecological model. ${ }^{17}$ The guide was arranged in five sections, consisting of 18 core items (with probes) covering the following domains: healthy bladder beliefs/attitudes, bladder knowledge acquisition, LUTS experience and care seeking, terminology, and public health messaging. The guide was piloted through mock focus groups coordinated with community partners.

Focus groups were audio-recorded and transcribed verbatim. After each focus group session, participants completed self-administered measures to characterize the sample in terms of demographics, physical/health conditions, and LUTS status.

\subsection{Data analysis and interpretation}

Data analysis and reporting were conducted in accordance with the Consolidated Criteria for Reporting Qualitative Research (COREQ) guidelines. ${ }^{18}$ Focus group transcripts were entered into Dedoose, a software program for facilitating the organization and coding of nonnumerical data (Version 8.0.35, SocioCultural Research Consultants, LLC, Los Angeles, CA). ${ }^{19}$ Guided by a four-member team, the iterative process of analysis used consensus building, involving (a) memoing transcripts, (b) using directed content analysis to formulate a priori deductive codes derived from the focus group guide, and (c) identifying emergent inductive codes. Disagreements were resolved through a consensus process of assessing fidelity to informants' accounts and consistency with previous analytic decisions.

For the purpose of this paper, a second layer of data analysis and interpretation of the "lay terminology" code was carried out using a transdisciplinary lens and inductive approach. After immersing in the data, a team of investigators consisting of a medical sociologist, behavioral psychologist, urological clinician researcher, and public health scientist used a consensus building approach to develop interpretive insights about the attributes of lay language and lay discourse. Findings were validated and elaborated upon by an 11-member community engagement panel comprised of women and adolescents, including two mother-daughter dyads and stakeholders from academic, public health, clinical, and 
social service settings. Additional insights were provided by SHARE investigators and the PLUS Consortium at large.

\subsection{IRB approval}

The study was approved by the University of Pennsylvania Institutional Review Board (IRB), which served as the central review board for six of the seven sites, and a local university IRB at the remaining site. All participants signed informed consent forms and received $\$ 50$ gift cards for their participation.

\section{3 | RESULTS}

\section{1 | Sample characteristics}

Forty-four focus groups were conducted with 360 adolescents and adult women, with each group comprised of 3 to 12 participants. The sample was diverse with respect to race, ethnicity, education, socioeconomic states, physical/health conditions, LUTS status, geography (urban/rural), and language. Characteristics of the sample are shown in Table 1.

\subsection{A repertoire of terms}

Lay discourse about bladder health and function is characterized by terminology used to talk about passing urine and qualities of the language employed to describe lower urinary tract function. Women of all ages have a repertoire of terms for bladder function and passing urine, including explicit functional terms (piss and pee), formal terms (void and urinate), polite euphemistic terms (using the restroom/ladies' room), and informal familiar terms (pee and gotta go), as well as cultural and regional metaphors and idioms (paying the water bill and throwing the waters). "Pee" was the most frequently endorsed lay term. "Urinate," while used infrequently, was the most referenced medical term. The variety of expressions for bladder function in the layperson's vocabulary appears to reflect a cumulative process with terms acquired early in life often remaining in use over the life course.

TABLE 1 Characteristics of participants

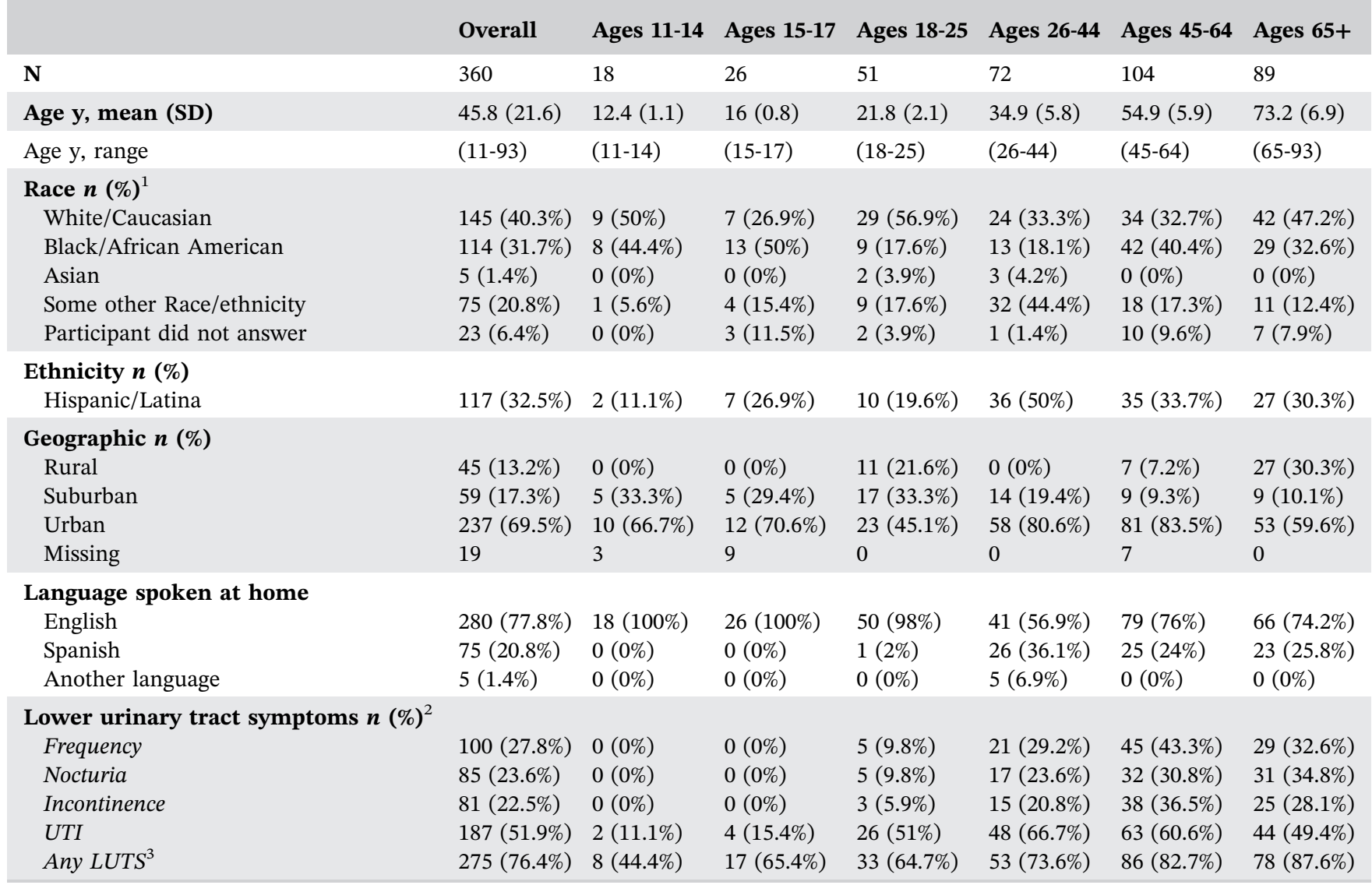

Abbreviations: LUTS, lower urinary tract symptoms; UTI, urinary tract infection.

${ }^{1}$ The question about race allowed participants to denote multiple races, such that the percentages do not always sum up to 100 .

${ }^{2}$ Based on responses to individual items of the LUTS Tool questionnaire (for adults) and the ICIQ CLUTS Survey (for adolescents).

${ }^{3}$ Any LUTS was defined as endorsement of any of the four LUTS items (frequency, nocturia, incontinence, and UTI). 


\section{BOX 1 Finding words}

- I feel like there's not really a term for other than like what you were saying, the medical term, but like people don't say "oh, I've had blank" to imply that they've had the need to urinate frequently. But I don't know. (Age Group: 18-25)

- People be like “oh, don't think about it, like or, or do a dance.” That's not helping me; like that's going to make me have to go to the bathroom even more. This is, this is like it really is uncomfortable like, it's like a, when you really hold it, it's like cramps. It's like a cramp. (Age Group: 15-17)

- I'll get pain but like on the side if I hold it too long. It starts telling me to where I have, I get like a side pain, kind of like a, not like an excruciating pain, kind of like a, a desire, like a, like a small little hip bruise something. Like you bruise yourself, just a small slight pain that I got to go. I got to go. I gotta go or I pee right here. (Age Group: 65+)

- You feel the urgency and the pressure to go. With me it's not a pain or anything like that... if it was a pain, you always be alert to it. You know you always like ooh, I'm hurting, I got to go. So, to me, it's not a pain or anything like that. It just, just an urgent. And it's kind of hard to describe going to the, you got to go to the restroom to urinate... that's a feeling you can't really describe because I think it affect people different ways. (Age Group: 65+]

\subsection{Finding words}

Participants often had difficulty finding words to talk about bladder function, describing rather than naming bladder experiences and uncomfortable sensations (Box 1). Although participants were aware that medical terms existed, the terms were not part of their vocabulary. Instead, there was a tendency to describe their experiences using familiar terminology related to other uncomfortable sensations. In addition, there was a recognition among participants that a single term may not capture individual variation in the experience of bladder sensations.

\section{4 | Social-historical contexts}

Lay terminology for bladder function is embedded in a social-historical context (Box 2). Some terms used in the past seem outdated and no longer in vogue. Similarly, changing social norms, practices and sensibilities introduced new terms into the lay conversation on bladder function. Shifts in lay terminology may reflect society-wide changes in overall lay discourse driven by technological innovations, popular culture, and a growing trend for informal and abbreviated language such as texting acronyms (BRB for "be right back" or "bathroom break") or emojis (faucet and toilet) to indicate one's intent to use the bathroom.

\subsection{Interpersonal and situational contexts}

Lay language for bladder health and function is contextual, with interpersonal context and social setting dictating word usage (Box 3). Participants described unspoken, commonly

\section{BOX 2 Social-historical contexts}

- What about when, umm, mothers used to say they're going to powder their nose?.. You don't hear that much anymore. (Age Group: 45-64)

- When we were growing up, no one ever said I have to go pee. That's a much more modern thing.... We always said tinkle when we had to go. I don't think I've ever heard anybody use the term urinate. (Age Group: 65+)

- I used to say I have to use the restroom or the bathroom, and then it seems like it became socially acceptable to say oh, I need to pee. (Age Group: 26-44)

- All my kids say they have to whiz, and they have a song about it, and yeah, they sing. Oh, actually, there is a punk band that has a song called Gotta Whiz and so all four of my kids sing that song when they have to go to the bathroom. (Age Group: 26-44) 


\section{BOX 3 Interpersonal and situational contexts}

- I think like if I'm with my family or closer friends, then I'll just be like, hey, I got to pee, like casual, but if I'm like asking a teacher, then I'll just like say, can I, may I use the restroom? Not like, I mean, it's kind of like the informal versus formal in my wording but yeah. I think it depends on who I'm with. (Age Group: 15-17)

- It depends on who you're with, you know? It's girls' night, we're all sitting around saying I gotta go piss, you know? It's vulgar in here (focus group), but it's just one of those (words) and then off we go. (Age Group: 45-64)

- If I'm talking to the kids, it's just I gotta pee really bad. That would be like our every-day language. But if I'm out, in public, I would just say I need to use the restroom ... For the most part, I think especially when you have children, you still kind of focus on the smaller words. (Age Group: 26-44)

- It depends on where I am. Like if I'm at my family's home, I just go to the bathroom because I'm at my in-laws, I just go to the bathroom. If I'm at work, you know I'll say I'm going to the restroom. And if I'm a public place, I just go to the bathroom, so. (Age Group: 26-44)

understood, situation-based "rules" for talking about bladder function. In personal, close-knit social groups such as family and friends, the use of colloquial terms such as "pee" or "going to pee" is common. In impersonal, loosely-knit, taskoriented, groups such as schools and the workplace, the use of formalized, polite terminology such as "using the restroom" or "going to the restroom" is preferred.

\section{6 | Emotional salience and affective valence}

Lay discourse for bladder function is affectively valent, meaning that its terminology can elicit feelings ranging from positive to negative (Box 4). The language used to describe bladder experiences can convey the underlying emotional salience of talking openly about behaviors related to private bodily functions. Life course variations were evident in the emotional salience of terminology used. When speaking with children, adults may intentionally use terms with positive affective valence to provide a reassuring context of toileting and engender positive feelings about bladder function. In contrast, terms with the potential to elicit negative emotional experiences appeared more commonly used among adolescents/young adults, possibly reflecting a tension between the appropriateness of conventional language for bladder function and the emotional impact of expressive terminology.

Participants used euphemisms to influence the emotional impact of talking about urination. For example, communication about one's need to pass urine in school or work settings typically involved excusing oneself from the room (or asking permission to be excused) and announcing where you are going (bathroom, restroom, ladies' room, girls' room, and down the hall) or why you are going (use the facilities). In addition, some women described using implicit terminology or simply not telling or needing to inform others what they are doing or where they are going.

\section{7 | Family and friend narratives}

Conversations about passing urine typically occur in family and friendship circles often in the form of storytelling, anecdotes and cautionary tales (Box 5). Among close female relatives, friends, and co-workers, advice is sought and given, and experiences are shared. In a similar way, networks of friends and colleagues share bladder experiences, offering advice and support.

\section{8 | Normalizing LUTS}

Beginning in childhood and extending across the life course, lay terminology and discourse can serve to normalize and minimize bladder issues. (Box 6) Participants often injected humor into accounts of incontinence. Similarly, the terminology used in lay narratives of nocturia and nocturnal enuresis belies the seriousness of these bladder function issues.

An unexpected emergent insight from the community engagement panel was how language shapes the conceptualization of bladder sensations and function and influences perceptions of acuity and the need to seek healthcare. The panel noted that participants' discourse about bladder issues reflected a continuum of severity and frequency, with medical language relevant to extreme examples and not mild episodic occurrences related to strenuous physical activity. Likewise, urine leakage and nighttime voiding were characterized as private issues or nuisances, primarily affecting women 


\section{BOX 4 Emotional salience and affective valence}

- Oftentimes, I don't even say that at all. Just say I'll be right back. I wouldn't even say I have to go to the restroom. Like if I'm at my own home and I have a friend, I guess, or something like that... (another participant) I do the same thing. I don't say I'm going to the restroom. I just say I'll be right back. (Age Group: 26-44)

- We say, umm, in the office going down the hall, I'll be back in a minute, going down the hall. Everybody just kinda accepts that as the bathroom. (Age Group: 26-44)

- Depending on who I'm talking to or who I'm talking about it, it's either pee, go to the bathroom or go potty... I say pee when I'm not at work and when I'm at work, I just say going to the bathroom, or I avoid making a comment about where I'm going. (Age Group: 18-25)

Positive affective valence when speaking with children:

- As a new parent, I constantly think of what terminology am I saying because that's what this person is going to learn. It's like oh, I want my son to feel comfortable to say whatever that thing is I'm going to figure out one time to tell him, so then he feels like it's not something I have to be embarrassed about. This is a function of my body and that's not something to be embarrassed about. (Age Group: 26 to 44)

- If you're around children, it depends on what you say how children relate to going to the bathroom. (Age Group: 65+)

- I think we reference it in our family going to the little girls' rooms, sometimes when the kids were little. (Age Group: 45 to 64)

- When I taught nursery school, you had to know what the terms that the kids used at home, so that you'd use the right term for that child. (Age Group: 65+)

Negative affective valence among adolescents/young adults:

- I always say I need to go to the restroom, and I have a friend that she says I need to pee, in front of me, it's so weird you're telling me; for me, it doesn't sound good. Although it's the same thing. (Age Group: 26 to 44)

- Sometimes I'll say it out loud, like what I have to do, some people will be, like they share their business too much, "Oh, you have to use the bathroom? You need to pull-up?" So, you just gotta keep it to yourself. (Age Group: 11 to 14)

- Boys, I know boys be like I got to take a piss.... Ooohhh (makes cringing noise...) Yeah, that's so nasty...I hate when boys say (that). (Age Group: 15 to 17)

of certain ages or life stages, and less often as a health concern, requiring professional care.

\section{4 | DISCUSSION}

Our exploration of lay terminology for bladder health and function revealed adolescent and adult women use a repertoire of terms, depending on the interpersonal and social context, suggesting their discourse is contextual and not transferable in the same way medical terminology is intended to be. Whereas development of consensus-based medical terminology is meant to support congruence, coherence and consistency in language usage, lay usage of language is highly variable, contextual, and may not hold the same meaning person to person. Findings also suggest lay terminology is shaped by historical and life course influences and affected by contemporary social norms and practices.

Lay discourse on bladder health and function appeared siloed in family and friendship circles using anecdotes, storytelling, and cautionary tales to warn women about the possibility of LUTS and inform them about approaches to self-care. Previous research found discussions of bladder health issues with close family members and friends could contribute to normalizing symptoms and diminish healthcare seeking behaviors. ${ }^{20}$

Adolescents and adult women often described rather than named bladder sensations or problems, suggesting 


\section{BOX 5 Family and friend narratives}

Family

- My mother-in-law talked more in my younger adult years, telling me about what she was experiencing and that's when I became more alert you know. She thought, she said, "Hey, as you grow older... when you laugh, you tinkle, when you sneeze, you tinkle." You know it's like it's no cause. It's just you got older you know, and that's how I began and having children, too, and having friends who did have bladder problems. That's how I learned then about some have five babies and like their muscles just collapsed. (Age Group: 65+)

- We have been struggling, from generation to generation, since my grandmother, my great-grandmother also, my mother, with bladder problems... That comes through the generations, is not something from now. So, we, for that reason, the bladder for us, has not been taboo. That is talked about, in the whole family, because it has been circulating in the family. (Age Group: 26 to 44)

- My mother used to tell me I guess there is some joke or saying... the queen never misses an opportunity. Whenever there's an opportunity to pee, you take it because keeping things coming out is good. That's kind of what I learned. But I feel like that happened later, because this will I'm sure come out in the course of the evening, I've been experiencing some unpleasantness with my own bladder in the past couple of years, so I'm always kind of thinking about, you know, when do I have to go, when do I have to plan to go. Where is there going to be an opportunity to go? So, this might happen later in my life. I don't, I don't really know, but I feel like that's what she told me, and I believe that. (Age Group: 45 to 64)

\section{Friends}

- A woman I know professionally had pie with me the day before I gave birth to my son, and handed me a gift bag for cute things for the baby and in it was also like a giant package of adult diapers ... she apologized profusely, like you know "if you're embarrassed, I'm so sorry," and then the next morning at like 7:15, of course, I'm like putting on adult diapers ... so if your friends are pregnant, please give them diapers. (Age Group: 26 to 44)

- We have this, in this friend group of mine, whenever we all go out drinking, you know, it's like don't break the seal. Because as soon as you break the seal, you're just going to have to keep going back and back and back and back and back to the bathroom. So, you know, we all have these little jokes and it's like we're getting ready to leave, go to the bathroom now please, you're going to pee all night, you know? (Age Group: 45 to 64)

- Actually, I have one of my friends tell me like last or a few weeks ago like she was like umm "I kept holding my bladder and now have infection, so now I had to like take care of it" and I was like oh, girl, well you got to go, like just go ahead. And we were in like she recently got rid of it, so we were in class and she was like I've been holding it all day, and I'm like you got to go because you just got over an infection, like tell the teacher that you have to go, so I think it's important that like when you got to go, you just go. (Age Group: 15 to 17)

lay vocabulary is more expressive than prescriptive when translating bladder experiences into words. This finding supports the results of a previous qualitative examination of lay persons' descriptions of urinary tract infections which revealed lay persons often have difficulty articulating symptoms. ${ }^{6}$

Terms for bladder function have the potential to evoke negative emotions, prompting an intentional and normative approach to their use. There appeared to be a preference for using language for urinary incontinence that may diminish emotional impact (leaking) and minimize culpability (accident). The same pattern was observed for nocturia and enuresis, with adolescents and adult women using less clinical terminology such as "night pees" and "pee dreams." Similarly, episodic bladder issues were characterized on a spectrum ranging from minor nuisances to burdensome problems, rather than labeled as clinically defined problems. This viewpoint is consistent with recent qualitative research on the toileting behavior of adult women characterizing the need to void often as a nuisance. ${ }^{21}$

Naming and characterizing bladder problems as medical disorders may be a stigmatizing and contested issue, reflecting a disconnection between specialized 


\section{BOX 6 Normalizing LUTS}

Injecting humor

- You teach the kids to say I had an accident. So, we joke with my mother because she has accidents, as well... I have heard males that are of my age, I'm in my mid-20s, say like when they like to make jokes like wet yourself. I've heard that. (Age Group: 26 to 44)

- I work with K through 3. We get a lot of accidents. (Group laughing.) And I try to be very respectful so that they you know honey, it's okay. Just go to the office. You'll be fine. Don't worry about it. (Group in agreement; Age Group: 45 to 64 )

- I couldn't get my keys out fast enough. Like I was running in the house while like having to go to the bathroom. I was running down my steps, almost peed on myself, like pee coming down, it's like oh, no, no, no. But it's, yeah. It's like oops, I peed on myself or I had an accident, or oh, geez. Let's not say anything to anybody. (Laughter; Age Group: 15 to 17)

- I was just going to say you know I think it's one of those things that we laugh about as just a sign of aging and kind of take it for granted that it's going to come around and I can remember when I first started working professionally and I was working with older women and they would make these comments about laughing and having leakage or sneezing and having leakage. (Age Group: 45 to 64)

Belying the seriousness of nocturia and nocturnal enuresis

- What do you call it when you wake up at night to go to the bathroom? Ahh, tinkle, tinkle little star. (Age Group: 11 to 14 )

- Had a case of the night pees last night three times or, you know, whatever. It doesn't happen often but when it does, there it is, the night pees. (Age Group: 26 to 44)

- Sometimes you're just too late, you just can't even - you do the one where you jump, and you sit on the side of the bed. You want to make it to the bathroom, but you just sit on the side of the bed, you just grip, and you know if you move, some of it's gonna come out, and then once it starts, it's no stopping it. (Age Group: 45 to 64)

- My roommate, she sleeps, and she sleeps, she sleeps really, really hard. So, I know this happened last week. She had an accident. I'm like what happened? She was like I was asleep, I had a pee dream. I feel like I was on the toilet. She was just like I couldn't hold it. It was something that she couldn't wake up. (Age Group: 26 to 44)

- Little tricklings, right. Now, for no apparent reason, (few women state, $\mathrm{mm}-\mathrm{hmm}$ ) and I don't wake up. Some people can wake up when they got to urinate. My thing was, as I was growing up, I couldn't wake up. (Age Group: $65+)$

professional knowledge and lay experience. Using lay language that minimizes culpability and normalizes symptoms is an underlying social process that may buffer the emotional impact of LUTS and lessen the potential for stigmatizing the experience. At the same, normalizing symptoms might reduce the perceived need to seek treatment or engage in behavioral changes. These observations align with research on how terminology shapes lay perceptions of the meaning and impact of disorders and treatment options including the negative emotional connotation lay persons may attribute to medical language for symptoms. ${ }^{22}$

A notable strength of this study is that it drew upon the experiences of a broad age range of adolescents and adult women of various racial and ethnic backgrounds from across the country. In addition, our sample comprised participants with various symptom experiences, including some with no experience of LUTS. However, due to the qualitative nature of the study, the findings are not generalizable to all adolescents and adult women or to women from other countries whose cultural perspectives on bladder health and function can differ from the views expressed in this US based study. To inform the work of bladder health professionals worldwide, future research could take an inclusive approach, exploring lay language and discourse across national boundaries and within other underrepresented US cultures (eg, 
Native American and Muslim American) and groups (eg, sexual gender and differently-abled) who are likely to have unique perspectives. Finally, it was not within the scope of this study to characterize lay terminology among male populations, a constituency whose discourse on bladder health and function may exhibit distinctive qualities not identified in the present study.

\section{5 | CONCLUSIONS}

Lay language for medical conditions often does not coincide with scientific medical terminology. ${ }^{6}$ Even when professional and lay persons use the same term, the meaning and interpretation can differ, and misunderstandings can occur. ${ }^{23}$ This issue is compounded by the subjective and sometimes idiomatic nature of lay terms, making it difficult to link them to corresponding scientific concepts or medical terminology. ${ }^{24}$ Our findings suggest an underlying social process of definitional discordance between lay and medical views of bladder problems, limiting clear understanding and successful communication about bladder health. Adolescents' and adult women's descriptive accounts of bladder health and function embody their lived experiences and therefore do not function to extend lay discourse beyond personal anecdotes to science or to translate stories of personal problems into issues of public health. Educating adolescents and adult women to shift from "problem-focused" conversations to "health-focused" discourse is a health promotion and health education issue. Public health messaging about bladder health literacy and healthpromoting behaviors is needed to transform the dialog from stigmatizing clinical conditions to healthy bladder habits.

These findings can be used to foster shared understandings between lay persons and medical professionals and inform the development and implementation of interventions to promote bladder health and prevent LUTS in women across the life course. Public health campaigns to promote bladder health and prevent LUTS could listen to the voices of adolescents and adult women, use lay anecdotal accounts as a vehicle to generate interest and engagement, focus on connecting with family-peer networks and avoid framing bladder issues solely from a clinical or pathologizing perspective. To better characterize the experiences and prevalence of bladder issues in adolescent and adult women, researchers could develop contextualized survey items and use lay language to clarify the meaning of medical terms. Terminology usage by researchers should be sensitive to the preferences and understandings of lay consumers of health information. ${ }^{25}$

Based on insights that emerged from focus groups and a community panel discussion, healthcare providers may wish to use terminology that is less stigmatizing and readily understood and preferred by patients. Clinicians could enhance patient-provider communication by placing more emphasis on the patient's story to gather and interpret health information. Finally, the advent of telehealth systems, health portals, and on-line health information resources is an impetus for developing and disseminating user friendly language and consumer health vocabularies to empower patients and to foster informed shared decision-making regarding bladder health. ${ }^{2-4}$

\section{ACKNOWLEDGMENTS}

We thank Jordan L. Thomas, BA, and Lindsey Behlman, BA, for their role in codebook development. We are grateful to the PLUS Research Consortium research coordinators, focus group moderators, other personnel at each center, and all the adolescents and women who participated in the SHARE focus groups.

The Prevention of Lower Urinary Tract Symptoms (PLUS) Research Consortium is supported by the National Institutes of Health (NIH) - National Institute of Diabetes and Digestive and Kidney Diseases (NIDDK) by cooperative agreements (grants U01DK106786, U01DK106853, U01DK106858, U01DK106898, U01DK106893, U01DK106827, U01DK106908, and U01DK106892). Additional funding from: National Institute on Aging, NIH Office on Research in Women's Health and the NIH Office of Behavioral and Social Science.

Prevention of Lower Urinary Tract Symptoms (PLUS) Research Consortium Members.

Loyola University Chicago, 2160S. 1st Avenue, Maywood, Il 60153-3328.

Multi-Principal Investigators: Linda Brubaker, MD, MS; Elizabeth Mueller, MD, MSME.

Investigators: Colleen M. Fitzgerald, MD, MS; Cecilia T. Hardacker MSN, RN, CNL; Jeni Hebert-Beirne, PhD, MPH; Missy Lavender, MBA; David A. Shoham, PhD.

University of Alabama at Birmingham, 1720 2nd Ave South, Birmingham, AL 35294.

Principal Investigator: Kathryn Burgio, PhD.

Investigators: Patricia S. Goode, MD, MSN; Cora Beth Lewis, MD; Alayne Markland, DO, MSc; Gerald McGwin, $\mathrm{PhD}$; Camille Vaughan, MD, Beverly Williams, PhD.

University of California San Diego, 9500 Gilman Drive, La Jolla, CA 92093-0021.

Principal Investigator: Emily S. Lukacz, MD. 
Investigators: Sheila Gahagan, MD, MPH; D. Yvette LaCoursiere, MD, MPH; Jesse N. Nodora, DrPH.

University of Michigan, 500 S. State Street, Ann Arbor, MI 48109.

Principal Investigator: Janis M. Miller, PhD, ANP-BC, FAAN.

Investigators: Lawrence Chin-I An, MD; Lisa Kane Low, PhD, CNM, FAAN.

University of Minnesota, 3 Morrill Hall, 100 Church St. S.E., Minneapolis MN 55455.

Multi-Principal Investigators: Bernard Harlow, PhD, Kyle Rudser, PhD.

Investigators: Sonya S. Brady, PhD; Haitao Chu, MD, PhD; John Connett, PhD; Melissa Constantine, PhD, MPAff; Cynthia Fok, MD, MPH; Sarah Lindberg, MPH; Todd Rockwood, PhD.

University of Pennsylvania, Urology, 3rd FL West, Perelman Bldg, 34th \& Spruce St, Philadelphia, PA 19104.

Principal Investigator: Diane Kaschak Newman, DNP, ANP-BC, FAAN.

Investigators: Amanda Berry, PhD, CRNP; C. Neill Epperson, MD; Kathryn H. Schmitz, PhD, MPH, FACSM, FTOS; Ariana L. Smith, MD; Ann Stapleton, MD, FIDSA, FACP; Jean Wyman, PhD, RN, FAAN.

Washington University in St. Louis, One Brookings Drive, St. Louis, MO 63130.

Principal Investigator: Siobhan Sutcliffe, PhD.

Investigators: Aimee James, PhD, MPH; Jerry Lowder, MD, MSc; Colleen McNicholas, DO, MSc; Mary Townsend, $\mathrm{ScD}$.

Yale University, PO Box 208058 New Haven, CT 065208058.

Principal Investigator: Leslie Rickey, MD.

Investigators: Deepa Camenga, MD, MHS; Toby Chai, MD; Shayna D. Cunningham, PhD; Jessica B. Lewis, LMFT, MPhil.

Steering Committee Chair: Mary H. Palmer, PhD, University of North Carolina.

NIH Program Office: National Institute of Diabetes and Digestive and Kidney Diseases, Division of Kidney, Urologic, and Hematologic Diseases, Bethesda, MD.

NIH Project Scientist: Tamara Bavendam MD, MS; Project Officer: Ziya Kirkali, MD; Scientific Advisors: Chris Mullins, PhD and Jenna Norton, PH.

\section{ORCID}

Beverly Rosa Williams (1) http://orcid.org/0000-0003-45359781

Diane K. Newman (D) http://orcid.org/0000-0002-50836397

Sonya S. Brady (1) http://orcid.org/0000-0001-8660-9308 Ariana L. Smith (D) http://orcid.org/0000-0002-9784-2559

\section{REFERENCES}

1. Goryachev S, Zeng-Treitler Q, Smith CA, et al. Making primarily professional terms more comprehensible to the lay audience. AMIA Annu Symp Proc. 2008;6:956.

2. Topac V, Stoicu-Tivadar V. Patient empowerment by increasing the understanding of medical language for lay users. Methods Inf Med. 2013;52:454-462.

3. Messai R, Simonet M, Bricon-Souf N, Mousseau M. Characterizing consumer health terminology in the breast cancer field. Stud Health Technol Inform. 2010;160:991-994.

4. Cook TS, Oh SC, Kahn CE Jr. Patients' use and evaluation of an online system to annotate radiology reports with lay language definitions. Acad Radiol. 2017;24:1169-1174.

5. Haylen BT, de Ridder D, Freeman RM, et al. International Urogynecological Association; International Continence Society. An International Urogynecological Association (IUGA)/ International Continence Society (ICS) joint report on the terminology for female pelvic floor dysfunction. Neurourol Urodyn. 2010;29:4-20.

6. Okamoto I, Prieto J, Avery M, et al. Intermittent catheter users' symptom identification, description and management of urinary tract infection: a qualitative study. BMJ Open. 2017;7:e016453.

7. Coyne KS, Harding G, Jumadilova Z, Weiss JP. Defining urinary urgency: patient descriptions of "gotta go. Neurourol Urodyn. 2012;31:455-459.

8. Coyne KS, Sexton CC, Kopp Z, et al. Assessing patients' descriptions of lower urinary tract symptoms (LUTS) and perspectives on treatment outcomes: results of qualitative research: patients' descriptions of LUTS and treatment outcomes. Int J Clin Prac. 2010;64:1260-1278.

9. Heeringa R, van Koeveringe GA, Winkens B, van Kerrebroeck PEV, de Wachter SGG. Do patients with OAB experience bladder sensations in the same way as healthy volunteers? a focus group investigation. Neurourol Urodyn. 2012;31:521-525.

10. Anger JT, Nissim HA, Le TX, et al. Women's experience with severe overactive bladder symptoms and treatment: Insight revealed from patient focus groups. Neurourol Urodyn. 2011;30:n/ a-n/a.

11. Uren AD, Cotterill N, Harding C, et al. Qualitative exploration of the patient experience of underactive bladder. Eur Urol. 2017;72:402-407.

12. Wang Y-H, Chen S-H, Jou H-J, Tsao L-I. Doing the best to control: the experiences of Taiwanese women with lower urinary tract symptoms. Nurs Res. 2011;60:66-72.

13. Siu JY. The illness experiences of women with overactive bladder in Hong Kong. Qual Health Res. 2014;24:801-810.

14. Eriksson I, Olofsson B, Gustafson Y, Fagerström L. Older women's experiences of suffering from urinary tract infections. J Clin Nurs. 2013;23:1385-1394.

15. Flower A, Bishop FL, Lewith G. How women manage recurrent urinary tract infections: an analysis of postings on a popular web forum. BMC Fam Pract. 2014;15:162.

16. Harlow BL, Bavendam TG, Palmer MH, et al. The prevention of lower urinary tract symptoms (PLUS) research consortium: a transdisciplinary approach toward promoting bladder health and preventing lower urinary tract symptoms in women across the life course. Journal of Women's Health. 2018;27:283-289. 
17. Brady SS, Bavendam TG, Berry A, et al. The prevention of lower urinary tract symptoms (PLUS) in girls and women: developing a conceptual framework for a prevention research agenda. Neurourol Urodyn. 2018;37:2951-2964.

18. Tong A, Sainsbury P, Craig J. Consolidated criteria for reporting qualitative research (COREQ): a 32-item checklist for interviews and focus groups. Int $J$ Qual Health Care. 2007;19:349-357.

19. Dedoose Version 8.0.35, web application for managing, analyzing, and presenting qualitative and mixed method research data. Los Angeles, CA: SocioCultural Research Consultants, LLC; 2018. www.dedoose.com

20. Siddiqui NY, Ammarell N, Wu JM, Sandoval JS, Bosworth HB. Urinary incontinence and health-seeking behavior among white, black, and Latina women. Female Pelvic Med Reconstr Surg. 2016;22:340-345.

21. Palmer MH, Wu JM, Marquez CS, Rupp B, Conover MM, Newman DK. A secret club": focus groups about women's toileting behaviors. BMC Womens Health. 2019;19:44.

22. O'Connor CM, Menendez ME, Hughes K, Ring D. Questionable word choice in scientific writing in orthopedic surgery. Arch Bone Jt Surg. 2017;5:231-234.
23. Nordby H. Medical explanations and lay conceptions of disease and illness in doctor-patient interaction. Theor Med Bioeth. 2008;29:357-370.

24. Keselman A, Smith CA, Divita G, et al. Consumer health concepts that do not map to the UMLS: where do they fit? J Am Med Inform Assoc. 2008;15:496-505.

25. Baker D, Anandhakrishnan A, Tuite-Dalton KA, et al. How to refer to people with disease in research outputs: The disconnection between academic practise and that preferred by people with multiple sclerosis. Multiple Scler Relat Disord. 2016;10:127-133.

How to cite this article: Williams BR, Nodora J, Newman DK, et al. I never knew anyone who peed on themselves on purpose: Exploring adolescent and adult women's lay language and discourse about bladder health and function. Neurourology and Urodynamics. 2020;39:225-236. https://doi.org/10.1002/nau.24174 